\title{
Effect of the Air-Water Interface on the Conformation of Amyloid Beta
}

\author{
Suman Samantray and David L. Cheung* \\ School of Chemistry, National University of Ireland Galway, Galway, H91 TK33, Ireland
}

\begin{abstract}
It has long been recognised that liquid interfaces, such as the air-water interface (AWI) can enhance formation of protein fibrils. This makes liquid interfaces attractive templates for fibril formation but fully realising this requires knowledge of protein behaviour at interfaces, which is currently lacking. To address this molecular dynamics simulation is used to investigate fragments of amyloid beta, a model fibril forming protein, at the air-water interface. At the air-water interface the enrichment of aggregation-prone helical conformations provides a mechanism for the enhancement of fibrillation at interfaces. The conformational ensemble at the air-water interface was also considerably reduced compared to bulk solution, due to the tendency of hydrophobic side chains partitioning into the air restricting the range of conformations. Little overlap between the conformational ensembles at the AWI and in bulk solution was found, suggesting that AWI induces the formation of different set of structures compared to bulk solution. The smaller A $\beta(16-$ $22)$ and $\mathrm{A} \beta(25-35)$ fragments show an increase in the propensity for ordered secondary structure at the air-water interface but with a increased propensity for turn over other motifs, illustrating the importance of intra-protein interactions for stabilising helical and extended conformations.
\end{abstract}




\section{INTRODUCTION}

The formation of amyloid fibrils (dense linear protein aggregates) is a common feature amongst proteins ${ }^{1,2}$. They first came to prominence due to their connection with a number of diseases ${ }^{3}$, such as Alzheimer's, in which the formation of plaques formed by amyloid fibrils was first observed, Parkinson's, and type-II diabetes. Coupled with its implications in disease, fibrils that perform a number of biological functions (functional fibrils) have been identified $^{4,5}$. These functions include formation of structural features, such as biofilms or insect egg cases, information transfer, and the storage of hormones. In many cases functional fibrils take advantage of the excellent material and mechanical properties of protein fibrils. Their properties have also prompted the use of fibrils as components in materials applications. Combining their strength with their biocompatibility has led to a number of applications ranging from biomaterials to electronics.

While amyloid fibrils can form in many environments it has been shown that liquid interfaces, such as air-water or oil-water interfaces, can greatly enhance their formation ${ }^{6-9}$. This is due to a combination of the (i) increased protein concentration at interfaces and (ii) interfaces stabilising conformations favourable for fibril formation ${ }^{10,11}$. Within the body there are a host of interfaces, e.g. cell membrane, surfaces of organelles, that can nucleate fibril formation. This has been implicated in a number of diseases, such as the disruption of membranes by aggregation of islet amyloid polypeptide (IAPP) leading to type-II diabetes ${ }^{12}$. Liquid interfaces have also been used as templates for the formation of ordered structures from a range of building blocks, both synthetic and natural. As such liquid interfaces provide an attractive environment for the formation of fibrils for use in many applications. To realise these applications we need to understand the fibrilliation process at interfaces, in particular understanding how the interfacial conformation of proteins can be related to their fibrillation. Study of the early stages of fibrillation, in particular the conformations adopted by proteins at interfaces will allow us to decouple the effect of the interface templating fibril-favouring conformations and identify intermediate states on the fibrillation pathway.

Investigation of protein conformation at interfaces is challenging experimentally, due to the small length scales involved. Surface sensitive techniques, such as sum frequency generation $^{13}$ (SFG), RIME $\mathrm{CD}^{14}$, and $\mathrm{SRCD}^{15}$, can give information on molecular structure at surfaces and interfaces. These, however, are ensemble techniques, so are averaged 
over all the protein molecules. This is a particular issue for intrinsically disordered proteins (IDPs), such as amyloid beta $(\mathrm{A} \beta)$, which lack a well-defined native structure. Understanding the interfacial behaviour of these proteins requires knowledge of the ensemble of different conformations they can exist in and how this is affected by interfaces.

Molecular dynamics simulation has become a powerful tool for the investigation of biomolecular structure. In particular, the use of advanced sampling techniques, such as replica exchange ${ }^{16}$ or metadynamics ${ }^{17}$, allow for the exhaustive sampling of conformations of IDPs. A number of previous studies have used these to investigate the structure of proteins on interfaces ${ }^{18-20}$ and surfaces ${ }^{21,22}$, giving new insight into the role of such environments in driving changes to protein structure. In particular for disordered proteins it has been shown that adsorption onto interfaces and surfaces can induce the formation of ordered structures, such as $\alpha$-helices or $\beta$-strands, which may then be prone to further aggregation.

To aid understanding of the fibrillation process it is common to investigate fragments of larger proteins. For $\mathrm{A} \beta$ commonly these include the $\mathrm{A} \beta(10-40)$ fragment, which lacks the Nterminal region which remains disordered following fibril formation ${ }^{23}$, A $\beta(16-22)$ fragment, which contains the central hydrophobic core of the protein, and A $\beta(25-35)$ fragment, which is the smallest fragment to show the same neurotoxic effects of the full protein ${ }^{24}$. While it may be expected that these fragments should mimic that of the full protein, in some cases these can show significantly different behaviour. For instance on gold surfaces the diphenylalanine motif in $\mathrm{A} \beta(16-22)$ shows different behaviour to that in the full protein ${ }^{25,26}$, which is responsible for contrasting effect of surfaces on the fibrillation of the fragment and full protein. This highlights the importance of larger protein structure on fragment behaviour. To understand this comparison of small and large fragments, in particular investigation of whether the fragment behaves in the same way in a larger molecule than when its on its own, is necessary.

In this paper the behaviour of three fragments of $\mathrm{A} \beta, \mathrm{A} \beta(16-22), \mathrm{A} \beta(25-35)$, and $\mathrm{A} \beta(10-$ 40 ), is investigated at the air-water interface (AWI), a model hydrophobic-hydrophilic interface. Comparison with the structures found in bulk solution shows that, in common with studies of other IDPs, the AWI induces the formation of ordered structures. This was primarily $\alpha$-helical for the largest fragment, significantly different to the structure found in bulk solution. For the smaller two fragments the similar secondary structure motifs were found on both the AWI and in bulk solution but with a higher probability of ordered structure at 
the AWI. This difference between the smaller and larger fragment highlights the importance of the larger protein in stabilising secondary structure formation.

\section{MODEL AND METHODOLOGY}

\section{A. Simulated system}

The simulated systems consist of a single protein molecule (A $\beta(16-22), \mathrm{A} \beta(25-35)$, or $\mathrm{A} \beta(10-40)$ fragment) in water. For $\mathrm{A} \beta(10-40)$ and $\mathrm{A} \beta(25-35)$ the initial peptide structures were taken from experimental NMR structures (1IYT ${ }^{27}$ and $1 \mathrm{QYT}^{28}$ ), with the first nine and last two residues removed for $\mathrm{A} \beta(10-40)$. The initial structure for $\mathrm{A} \beta(16-22)$ was taken to be a linear chain constructed using Avogadro. Protonation states of the termini and for polarisable residues were set appropriate for $\mathrm{pH}=7$. For the AWI simulations this was placed

in a water slab with initial size $80 \AA \times 80 \AA \times 60 \AA, 60 \AA \times 60 \AA \times 50 \AA$, and $60 \AA \times 60 \AA \times 50 \AA$ for $\mathrm{A} \beta(10-40) \mathrm{A} \beta(16-22)$ and $\mathrm{A} \beta(25-35)$ respectively, with the box tripled in the $z$-direction to give a vacuum layer on each side of the slab. For the bulk simulations the protein was was placed in a cubic water box with side length $70 \AA, 40 \AA$, and $50 \AA$ for A $\beta(10-40) \mathrm{A} \beta(16-22)$ and $\mathrm{A} \beta(25-35)$ respectively.

\section{B. Simulation method}

In order to enhance sampling of protein conformations replica exchange with solute tempering (REST) was employed ${ }^{29,30}$. This is a variation on replica exchange molecular dynamics $^{31}$, where the temperature varies only for a subset of the system, in this case the protein. The temperature scaling was performed by scaling the protein-protein and proteinsolvent interactions by a factor depending on the effective temperature. Specifically the potential energy was given by ${ }^{30}$

$$
E_{i}=\beta_{i} E_{p p}+\beta_{i}^{1 / 2} E_{p s}+E_{s s}
$$

where $E_{p p}, E_{p s}$, and $E_{s s}$ are the protein-protein, protein-solvent, and solvent-solvent interaction and the scaling factor $\beta_{i}=T_{0} / T_{i}$. For all systems the effective temperature was in the range $300 \mathrm{~K}$ to $440 \mathrm{~K}$, slightly wider than used in previous REST simulations of the $\mathrm{A} \beta(10-$ 40) fragment ${ }^{32}$, with the scaling factors and effective temperatures for the different systems 
are given in Table I. Exchange attempts between neighbouring replicas were attempted every 500 time steps (1 ps). Transitions between different temperatures and acceptance probabilities are given in the appendix (Figure 9 and Table V).

\begin{tabular}{|c|c|c|c|}
\hline & & $N_{\text {replic }}$ & Scaling factors \\
\hline \multirow{5}{*}{$\mathrm{A} \beta(10-40)$} & \multirow{3}{*}{ AWI } & \multirow{3}{*}{12} & $1(300 \mathrm{~K}), 0.966(311 \mathrm{~K}), 0.932(322 \mathrm{~K}), 0.9(333 \mathrm{~K}), 0.867(345 \mathrm{~K})$ \\
\hline & & & $0.84(357 \mathrm{~K}), 0.811(370 \mathrm{~K}), 0.784(383 \mathrm{~K}), 0.757(396 \mathrm{~K}), 0.731(410 \mathrm{~K})$ \\
\hline & & & $0.706(425 \mathrm{~K}), 0.682(440 \mathrm{~K})$ \\
\hline & \multirow{2}{*}{ Solution } & \multirow{2}{*}{10} & $1(300 \mathrm{~K}), 0.956(313 \mathrm{~K}), 0.918(327 \mathrm{~K}), 0.88(341 \mathrm{~K}), 0.843(355 \mathrm{~K})$ \\
\hline & & & $0.808(371 \mathrm{~K}), 0.775(387 \mathrm{~K}), 0.742(404 \mathrm{~K}), 0.711(422 \mathrm{~K}), 0.682(440 \mathrm{~K})$ \\
\hline \multirow{4}{*}{$\mathrm{A} \beta(16-22)$} & \multirow{2}{*}{ AWI } & \multirow{2}{*}{6} & $1(300 \mathrm{~K}), 0.926(324 \mathrm{~K}), 0.858(350 \mathrm{~K})$ \\
\hline & & & $0.795(377 \mathrm{~K}), 0.736(408 \mathrm{~K}), 0.682(440 \mathrm{~K})$ \\
\hline & \multirow{2}{*}{ Solution } & \multirow{2}{*}{6} & $1(300 \mathrm{~K}), 0.926(324 \mathrm{~K}), 0.858(350 \mathrm{~K})$ \\
\hline & & & $0.795(377 \mathrm{~K}), 0.736(408 \mathrm{~K}), 0.682(440 \mathrm{~K})$ \\
\hline \multirow{4}{*}{$\mathrm{A} \beta(25-35)$} & \multirow{2}{*}{ AWI } & \multirow{2}{*}{8} & $1(300 \mathrm{~K}), 0.947(319 \mathrm{~K}), 0.896(335 \mathrm{~K}), 0.849(354 \mathrm{~K})$ \\
\hline & & & $0.803(373 \mathrm{~K}), 0.761(394 \mathrm{~K}), 0.72(417 \mathrm{~K}), 0.682(440 \mathrm{~K})$ \\
\hline & \multirow{2}{*}{ Solution } & \multirow{2}{*}{8} & $1(300 \mathrm{~K}), 0.947(319 \mathrm{~K}), 0.896(335 \mathrm{~K}), 0.849(354 \mathrm{~K})$ \\
\hline & & & $0.803(373 \mathrm{~K}), 0.761(394 \mathrm{~K}), 0.72(417 \mathrm{~K}), 0.682(440 \mathrm{~K})$ \\
\hline
\end{tabular}

TABLE I. REST scaling factors and effective temperatures.

Interfacial simulations were performed in the $N V T$-ensemble with the temperature controlled using a velocity rescaling algorithm ${ }^{33}$, with a relaxation time of $0.2 \mathrm{ps}$. Bulk simulations were performed in the $N p T$-ensemble using the Parrinello-Rahman barostat ${ }^{34}$ (relaxation time $2 \mathrm{ps}$ ) to control the pressure. All simulations were performed at a temperature of $300 \mathrm{~K}$ and the bulk simulations had a pressure of $1 \mathrm{~atm}$. Periodic boundary conditions where used, with a cutoff of $12 \AA$ for the van der Waals and short-range electrostatic interactions. Long-range electrostatic interactions were evaluated using a Particle Mesh Ewald ${ }^{35}$ sum with a Fourier spacing of $0.16 \mathrm{~nm}$. Reciprocal space grids of $36 \times 36 \times 36$ (bulk solution) and $40 \times 40 \times 160$ (surface) were used. The equations of motion were integrated using a timestep of $2 \mathrm{fs}$, with the LINCS algorithm use to constrain bond lengths ${ }^{36}$. Simulations were performed using the Gromacs simulation package (version 4.6.7) ${ }^{37-39}$, using the PLUMED 
library $^{40}$ to implement REST simulations.

Simulation lengths were $400 \mathrm{~ns}$ for the interface simulations and $500 \mathrm{~ns}$ for the bulk simulation. Equilibration was judged from considering the number unique conformations found from cluster analysis (Figure 10) using the method of Daura et a ${ }^{41}$ Conformations were partitioned into non-overlapping clusters based on the root-mean squared difference (RMSD) between $\mathrm{C}_{\alpha}$ positions (two conformations were in the same cluster if the RMSD was less than $3 \AA$ ). Equilibration being achieved once the number of low energy clusters (with free energy within $3 \mathrm{kcal} \mathrm{mol}^{-1}$ of the most populated cluster) had plateaued. Following this the simulations were run for a further $200 \mathrm{~ns}$, with analysis performed over this period (unless otherwise stated).

\section{Analysis}

Analysis of the simulations was performed using a combination of standard Gromacs utilities, custom-written python scripts using the MDAnalysis library ${ }^{42}$, and VMD (visual molecular dynamics $)^{43}$. The secondary structure analysis was performed using the STRIDE algorithm $^{44}$. Similarity to helices was also analysed through determining the number of $\alpha$-helical and 3/10-helical hydrogen bonds ${ }^{21}$

$$
\begin{aligned}
N_{\alpha-H B} & =\sum_{i=1}^{N_{H B}} \frac{1-\left(r_{i} / r_{0}\right)^{n}}{1-\left(r_{i} / r_{0}\right)^{m}} \\
N_{3 / 10-H B} & =\sum_{i=1}^{N_{H B}} \frac{1-\left(r_{i} / r_{0}\right)^{n}}{1-\left(r_{i} / r_{0}\right)^{m}}
\end{aligned}
$$

where $r_{0}=2.5 \AA, n=8, m=12$, and the sums run over all potential $\alpha$-helical (equation 2a) and 3/10-helical (equation 2b) hydrogen bonds, i.e. between backbone carbonyl oxygens and amine hydrogens separated by 4 or 3 residues respectively. The similarity to $\beta$-strands was analysed through the dihedral offset function

$$
D H=\frac{1}{2} \sum_{i=1}^{N-1}\left(1+\cos \left(\phi_{i}-\phi_{r e f}\right)\right)+\left(1+\cos \left(\psi_{i}-\psi_{\text {ref }}\right)\right) .
$$

where the sum runs over the $\phi$ and $\psi$ angles of the protein residues and the reference angles are $\phi_{\text {ref }}=-2.36 \mathrm{rad}$ and $\psi_{\text {ref }}=2.36 \mathrm{rad}$, corresponding to an ideal $\beta$-strand with alternating residues on opposite sides of the protein backbone. 
Protein size was characterised through the radius of gyration

$$
R_{g}^{2}=\frac{1}{N} \sum_{i=1}^{N}\left(\boldsymbol{r}_{i}-\boldsymbol{r}^{\mathrm{com}}\right)^{2}
$$

where $\boldsymbol{r}_{i}$ is the position of the $i$ th atom and $\boldsymbol{r}^{\text {com }}$ is the protein centre of mass and the sum runs over atoms in the protein and the eigenvalues of the gyration tensor

$$
G_{\alpha \beta}^{2}=\frac{1}{N} \sum_{i=1}^{N}\left(r_{i \alpha}-r_{\alpha}^{c o m}\right)\left(r_{\beta}-r_{\beta}^{c o m}\right), \alpha, \beta=x, y, z .
$$

Formation of compact structures can also be investigated through the number of contacts between $\mathrm{C} \gamma$ atoms calculated using

$$
N_{C \gamma}=\sum_{i}^{N} \sum_{j>i}^{N} f_{\text {switch }}\left(r_{i j}\right)
$$

where the double summation runs over $\mathrm{C} \gamma$ atoms on different residues and the switching function is given by

$$
f_{\text {switch }}(r)=\frac{1-\left(r / r_{0}\right)^{n}}{1-\left(r / r_{0}\right)^{m}}
$$

where $m=12, n=8$ and $r_{0}=4.5 \AA$. Contacts between $\mathrm{C} \alpha$ atoms $\left(N_{C \gamma}\right)$ are calculated similarly (with $r_{0}=8 \AA$ ). The conformational ensemble was analysed from a cluster analysis, using the method of Daura et $a l^{41}$, using a cut off of $3 \AA$. Unless otherwise stated analysis was performed for the $\beta=1$ replica (the only physically relevant one).

\section{RESULTS}

\section{A. The Air-Water Interface Induces Formation of Helical Structures in Amyloid- $\beta$}

Adsorption onto the air-water interface significantly changes the structure of A $\beta(10-40)$. The secondary structure (Figure 1(a)) shows large differences between AWI and bulk solution, even from the same $\alpha$-helical starting structure. At the interface the protein adopts a mixture of conformations, including ones with a high $\alpha$-helix content. The $\alpha$-helical conformations typically have two helical regions (V12-D23 and A30-V36). The formation of $\alpha$-helical structures is consistent with previous experimental studies of $\mathrm{A} \beta^{8,45}$, which have identified the formation of helical structures that may act as intermediate states for fibrillation on liquid interfaces. In bulk solution, after the initial equilibration period, there are 
no $\alpha$-helical conformations. Rather the protein adopts a mixture of $\beta$-strand and disordered conformations.
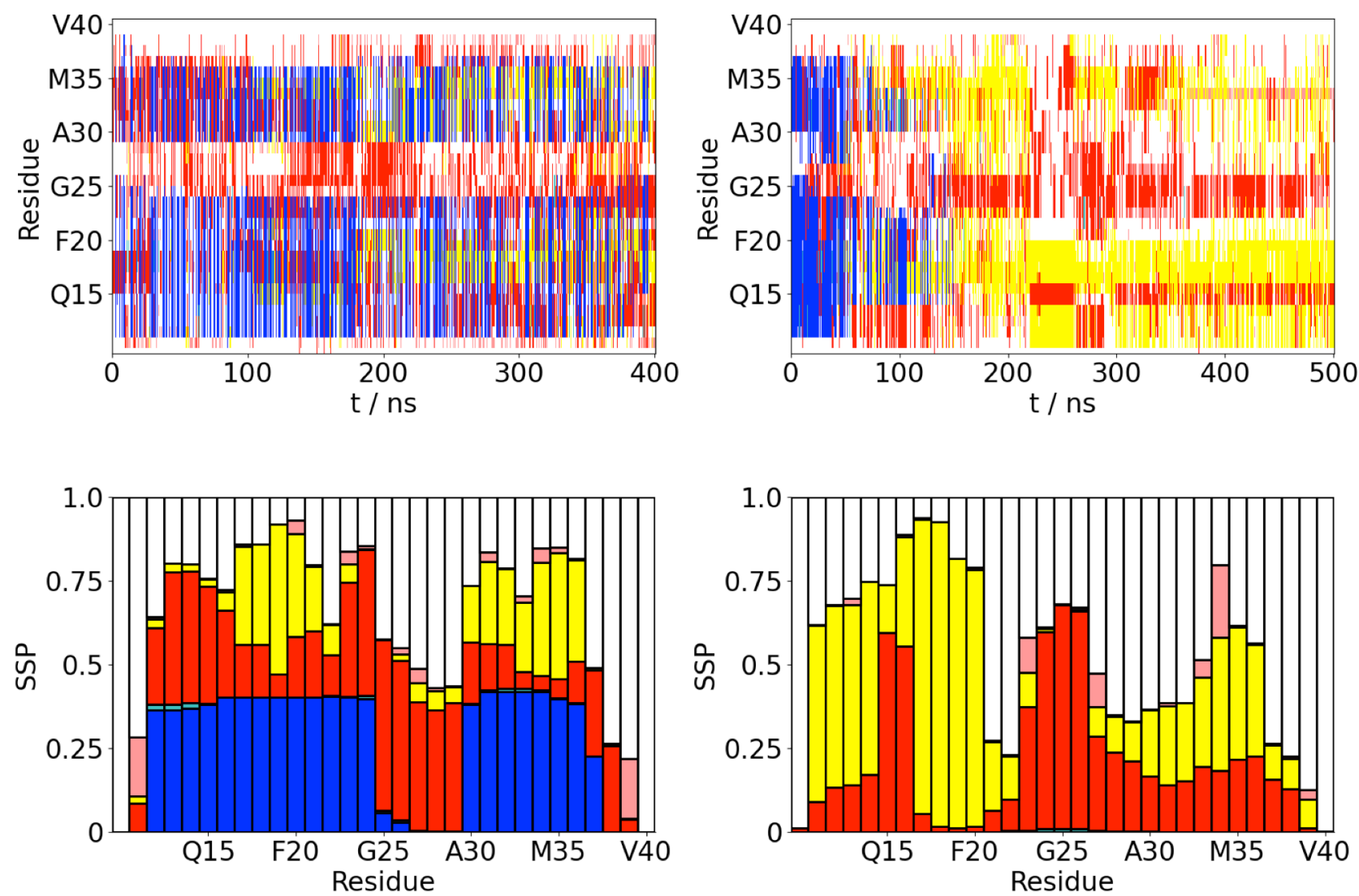

FIG. 1. (a) Time variation of secondary structure for $\mathrm{A} \beta(10-40)$ at AWI (left) and in bulk solution (right). $\alpha$-helix, $\beta$-strand, turn, 3/10-helix, and random coil (disordered) denoted by blue, yellow, red, cyan, and white respectively. (b) Propensity for different secondary structure motifs (both ordered and random coil) for each residue (averaged over last 200 ns of simulations). $\alpha$-helix, $\beta$-strand, turn, 3/10-helix, and random coil (disordered) denoted by blue, yellow, red, cyan, and white respectively.

The changes in the protein structure can also be seen from the propensity for different secondary structure motifs (Figure 1(b)). At the AWI regions of higher $\alpha$-helix propensity can be seen, consistent with the time series of the secondary structure. Notably no residue has an $\alpha$-helix propensity above $50 \%$. There are also some regions (L17-A21 and I31-V36) that have a significant propensity for $\beta$-strand formation. These are both contained within 
the $\beta$-strand regions in the $\mathrm{A} \beta(1-40)$ fibril $^{23}$.

In bulk solution there is a region of high $\beta$-strand propensity near the N-terminus (E11H14 and L17-F20), with the remainder of the protein being less ordered. Notably there is lower propensity for $\beta$-strand formation towards the C-terminal end of the peptide. Unlike the AWI there is no $\alpha$-helical regions. For both AWI and bulk solution there are also regions of the protein, such as the terminal residues and F20-A21 in bulk solution, which adopt largely disordered conformations for most of the simulation (shown by white in the SSP plot).

The tertiary structure of $\mathrm{A} \beta(10-40)$ is altered at the AWI (Table II). At the AWI the protein is slightly more compact, with $R_{g}$ and $G_{\max }$ being larger than in bulk solution. The more compact structure is also evidenced by the higher number of $\mathrm{C}_{\alpha}$ contacts. Notably the number of $\mathrm{C}_{\gamma}$ contacts is similar in both environments, suggesting that differences in protein structure are reflected largely in the backbone conformation than the packing of the side chains. Consistent with the differences in the secondary structures at the AWI the number of helical hydrogen bonds (both $\alpha$-helix and 3/10-helix) is higher and the dihedral offset $(D H)$ is lower than in bulk solution.

\begin{tabular}{lcc}
\hline & AWI & Solution \\
\hline$R_{g} / \AA$ & $10.7 \pm 1.6$ & $11.5 \pm 1.8$ \\
$G_{\text {max }} / \AA$ & $8.9 \pm 2.0$ & $9.7 \pm 2.1$ \\
$G_{\text {mid }} / \AA$ & $5.0 \pm 0.7$ & $5.0 \pm 0.9$ \\
$G_{\text {min }} / \AA$ & $3.4 \pm 0.4$ & $3.4 \pm 0.4$ \\
\hline$N_{C \alpha}$ & $162 \pm 18$ & $148 \pm 14$ \\
$N_{C \gamma}$ & $39 \pm 6$ & $37 \pm 5$ \\
\hline$N_{\alpha-H B}$ & $5.8 \pm 6.8$ & $0.5 \pm 0.4$ \\
$N_{3-10}$ & $4.6 \pm 3.8$ & $1.5 \pm 0.6$ \\
$D H$ & $36 \pm 9$ & $46 \pm 2$ \\
\hline
\end{tabular}

TABLE II. Structure of A $\beta(10-40)$ at AWI and bulk solution. Quoted uncertainties estimated from standard deviation.

The difference in the secondary and tertiary structure of $\mathrm{A} \beta(10-40)$ is driven by the differences in intramolecular interactions, in particular backbone hydrogen bonding, in these 
environments. Shown in Figure 2 are the probabilities of backbone hydrogen bond formation between the different residues. At the AWI hydrogen bonds consistent with $\alpha$-helix formation are more probable than in bulk solution, consistent with the higher $\alpha$-helix propensity (Figure 1(b)). The probability of these hydrogen bonds are $<50 \%$, showing that the $\alpha$ helical structures are still in a minority. In bulk solution there is a significant probability of hydrogen bonding between the (E11-H14 and L17-F20) $\beta$-strand regions, consistent with the formation of an intramolecular anti-parallel beta sheet. Outside of this the hydrogen bond probabilities are typically lower than at the AWI suggesting that a hydrophobic interface induces the formation of more ordered structures.

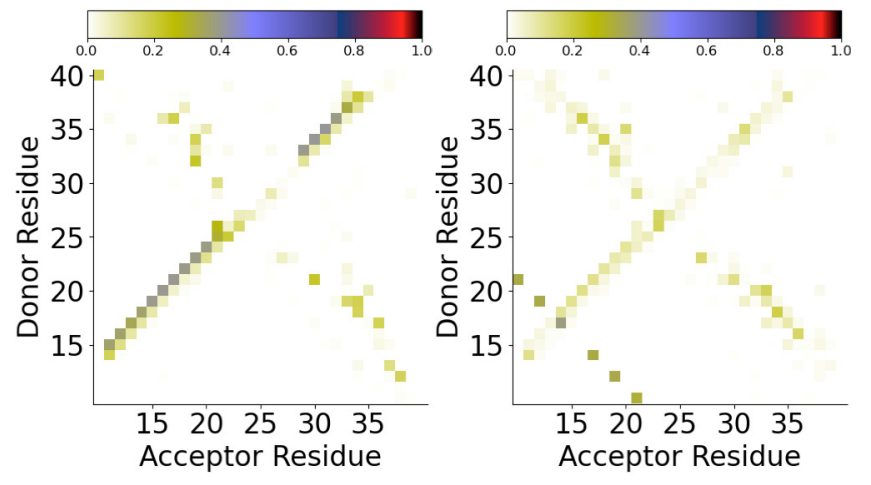

FIG. 2. Backbone hydrogen bond map for $\mathrm{A} \beta(10-40)$ at AWI (left) and in bulk solution (right).

The formation of $\alpha$-helices at hydrophobic interfaces, which has been observed in a number of previous studies ${ }^{20,46,47}$, is typically ascribed to the partitioning of hydrophobic residues into the hydrophobic media. Representative simulation snapshots (Figure 3(a)) suggest that this holds for $\mathrm{A} \beta(10-40)$. In all cases (for both $\alpha$-helix and $\beta$-strand rich conformations) hydrophobic residues typically lie near the AWI or in the air region.

The partitioning of the hydrophobic residues can be assessed quantitively through the orientation of each side chain (Figure 3(b)). This was defined as the angle between the interface normal, taken to be the $z$-axis and the vector joining the $\mathrm{C}_{\alpha}$ atom and terminal heavy atom in the side chain for each residue. Typically hydrophobic residues orient towards the air-water interface. Consideration of the two principal $\alpha$-helical regions (Figure 3(c)) shows that in the first of these (V12-D23) forms an amphipathic helix, with a predominately hydrophobic face (consisting of H13, K16, L17, F20, and A21). This hydrophobic face may 

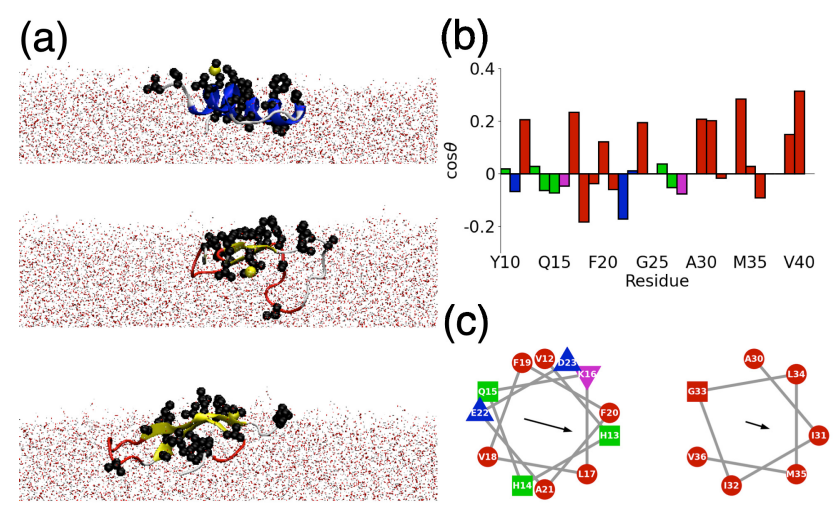

(d) 0.2

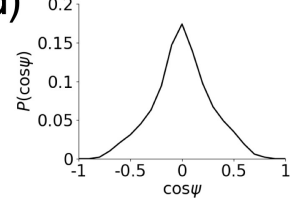

FIG. 3. A $\beta(10-40)$ structure at AWI. (a) Representative simulation snapshots, corresponding to the most common probable structures from cluster analysis. Hydrophobic side chains are highlighted as VDW spheres. (b) Side chain orientation. Red, green, blue, and magenta denote hydrophobic, polar, negatively-charged, and positively charged residues respectively. (c) Helical wheel plots for $\alpha$-helical regions (V12-D23 and A30-V36). Colours as in (b). (d) Probability histogram of helix orientation relative to AWII $(\cos \psi)$.

act as a hotspot for aggregation between neighbouring molecules on the AWI, increasing the rate of fibrillation. The second helical region (A30-V36) is largely hydrophobic (being drawn from the more hydrophobic C-terminus of the protein).

As can be seen from the snapshots the helices also tend to lie in the plane of the AWI. This can be assessed quantitatively through the angle $\psi$ between the helix axis and the interface normal. The average $\cos \psi=0 \pm 0.3$ consistent with the helix lying in the interface plane. This is also shown by the histogram of $\cos \psi$ (Figure 3(d)), which is peaked around $\cos \psi=0$. Similar behaviour was seen for the insulin B-chain at the air-water interface ${ }^{20}$

\section{B. Effect of Air-Water Interface on the Conformational Ensemble of $\mathbf{A} \beta$}

As an intrinsically disordered protein $\mathrm{A} \beta$ exists in an ensemble of different conformations, which can be modified through adsorption onto interfaces. Using cluster analysis the size of 
the conformational ensemble and typical structures in these different environments can be examined. There is a substantial reduction in the number of distinct conformations at the AWI compared to bulk solution (256 vs 647 ). This shows that adsorption to the interface restricts the number of conformations the protein can adopt, likely driven by the preferred partitioning of the hydrophobic side chains into air.

Shown in Figure 4(a) are the probability of different clusters for the AWI and bulk solution. While in both environments the first cluster is significantly more probable than the others, it is still $<50 \%$ showing that there is not a single predominant structure in both environments. Despite the reduction in the total numbers of conformations at the AWI, the is decrease in probability with cluster index is slower than in bulk solution. Comparison of the structures of the different clusters (Figure 4(b)) shows that the most common cluster at the AWI is $\alpha$-helical rich but the other common clusters have a higher $\beta$-strand content. This is consistent with the enriched formation of aggregation prone helical intermediates at the AWI. In bulk solution there are no $\alpha$-helical conformations amongst the most common clusters.

The different hydrogen bonding patterns between the AWI and bulk solution (Figure 2) are also apparent when we consider the hydrogen bonds formed in the different clusters (Table III). At the AWI the top ranked cluster has a number of $\alpha$-helical hydrogen bonds. It, and other clusters with $\alpha$-helical structures, has significantly more hydrogen bonds than the other clusters at the AWI and those found in bulk solution (Figure 5). The increase in the number hydrogen bonds has been seen for other proteins that form $\alpha$-helices at interfaces ${ }^{20}$, and reflects the increase in hydrogen bond strength at interfaces. Other clusters found at the AWI also show different hydrogen bonding patterns to those in bulk solution. In particular hydrogen bonds between residues at the N- and C-termini (Y10-V40, V12-G38) are found which suggests increased interactions between the two termini. Hydrogen bonds between the residues near the termini are less common in the most common solution conformations.

To investigate the difference between the conformational ensembles at the AWI and in bulk solution, the probability of finding each solution-like conformation in the AWI simulation is determined. Following previous work ${ }^{22}$ the $\mathrm{C}_{\alpha}$ - $\mathrm{C}_{\alpha}$ distance root mean-squared deviation (DRMSD) is calculated between each saved conformation from the AWI simulation and the clusters found in bulk solution, with the conformations matching if DRMSD $\leq 3 \AA$. Similar to previous study of the model fibril forming polypeptide hIAPP on hydrophobic 


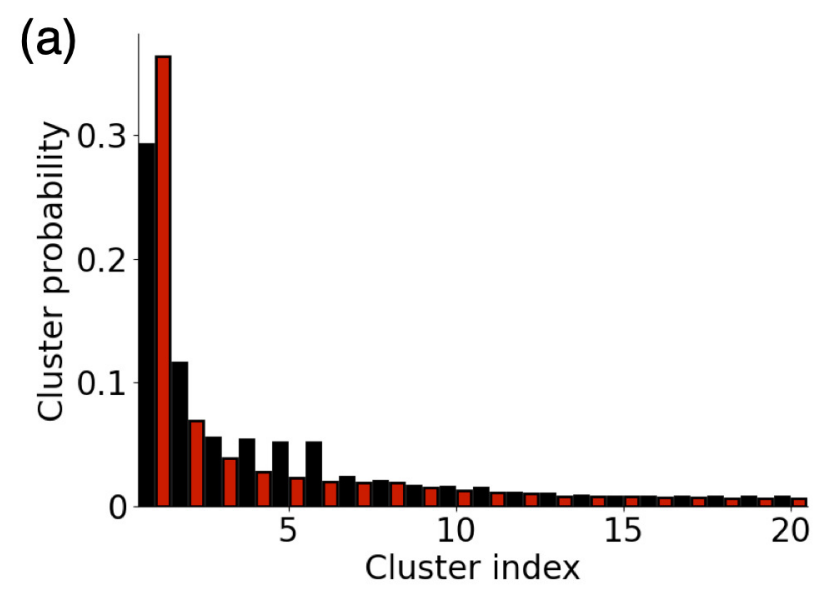

(b)
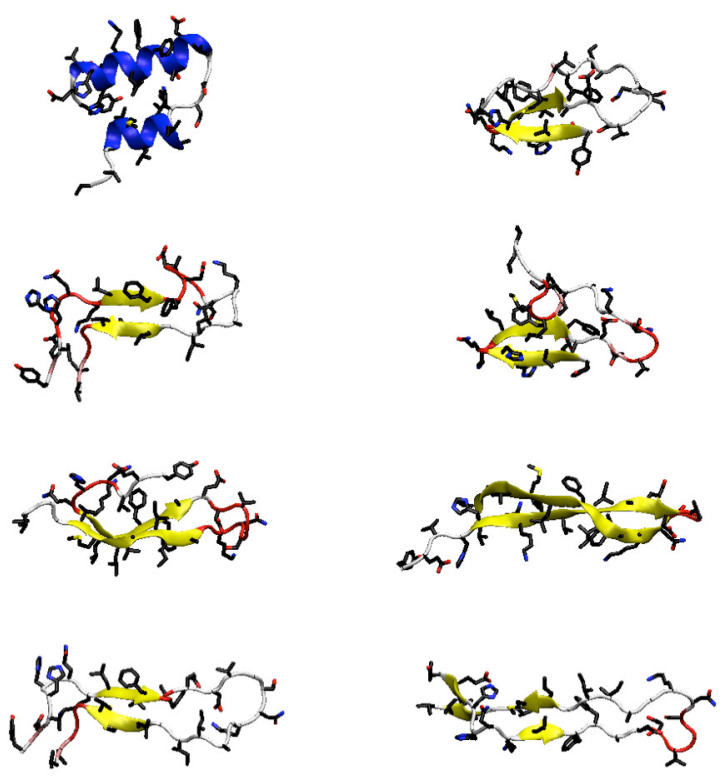

FIG. 4. (a) Probability of different clusters for $\mathrm{A} \beta(10-40)$ at AWI (black) and in bulk solution (red). (b) Snapshots showing higher ranked clusters for A $\beta(10-40)$ at AWI (left) and in bulk solution (right).

surfaces, generally the conformations formed at the AWI do not typically correspond to those found in bulk solution, with $\sim 66 \%$ of the conformations found at the interface having a DRMSD $>3 \AA$ from any solution conformation. This suggests that the AWI induces the formation of conformations that are qualitatively different to those found in bulk solution. This is similar to behaviour seen for other IDPs on hydrophobic interfaces but differs from the behaviour of $\mathrm{A} \beta$ on more hydrophilic gold $\operatorname{surfaces}^{26}$, suggesting that interfacial hydrophobicity plays a major role in determining the protein conformation. The only solution-like 


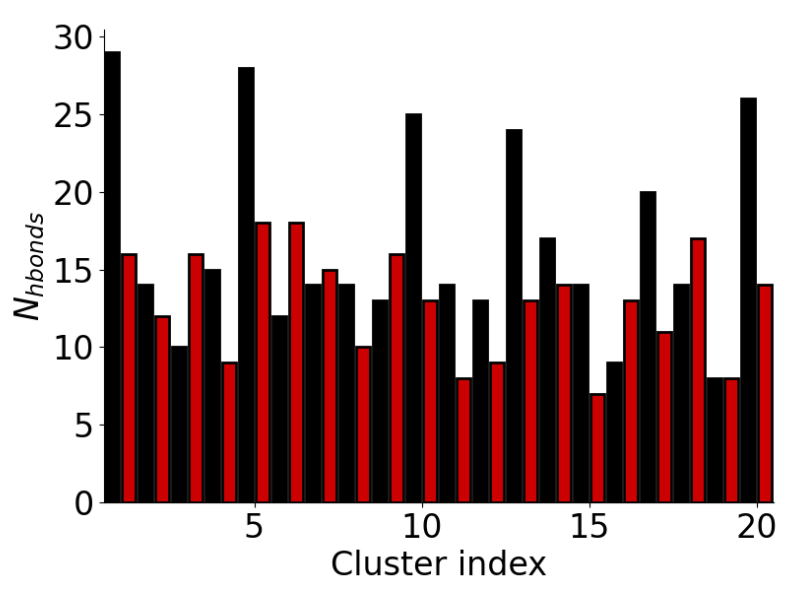

FIG. 5. Number of hydrogen bonds in clusters for A $\beta(10-40)$ at AWI (black) and in bulk solution (red).

conformations (Figure 6) that are found with a probability greater than 0.01 correspond to cluster IDs 506 ( $p=0.03), 550$ (0.02), 571 (0.11), 594 (0.01), and 643 (0.02), where increasing ID corresponds to decreasing probability for these clusters in bulk solution. This indicates that solution-like conformations found at the AWI do not correspond to the most commonly observed conformations in solution. The solution-like clusters typically are either $\beta$-strand or random coil, suggesting the the aggregation prone $\alpha$-helical conformations are induced at the air-water interface and not present in bulk solution.

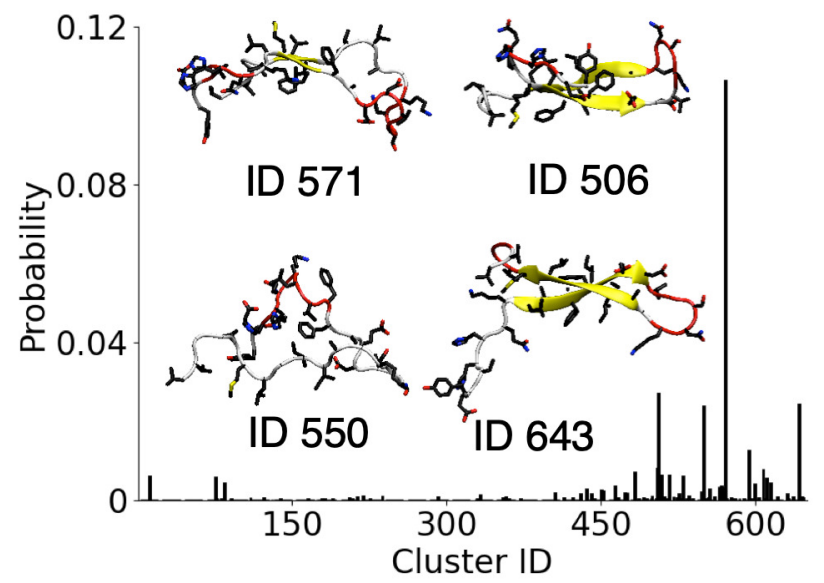

FIG. 6. Probability of A $\beta(10-40)$ solution conformations (by cluster ID) found in AWI simulation. Insets show snapshots of most probable solution-like conformations at AWI. 
Cluster ID $N_{\text {hbonds }}$ Hydrogen bond list

AWI

\begin{tabular}{|c|c|c|}
\hline 1 & 29 & 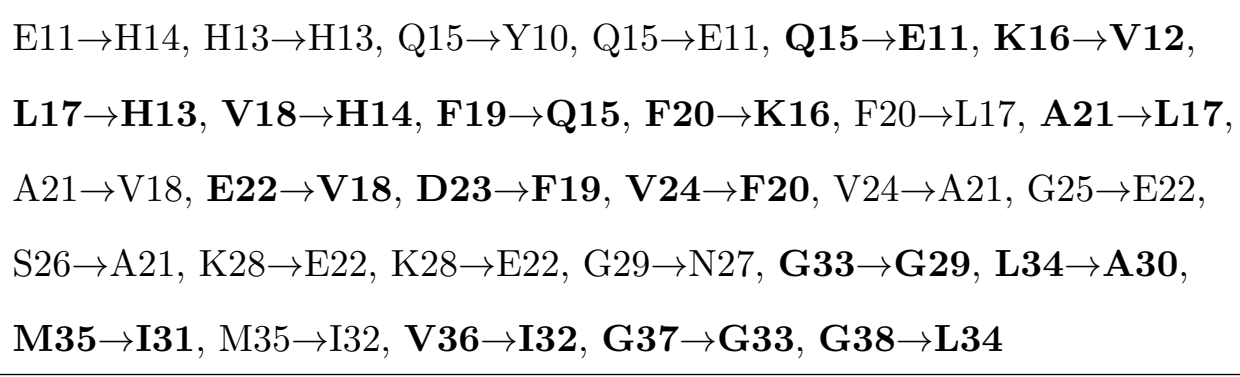 \\
\hline 2 & 14 & $\begin{array}{l}\mathrm{V} 12 \rightarrow \mathrm{G} 38, \mathrm{H} 13 \rightarrow \mathrm{G} 37, \mathrm{H} 14 \rightarrow \mathrm{H} 13, \mathrm{Q} 15 \rightarrow \mathrm{H} 14, \mathrm{~K} 16 \rightarrow \mathrm{G} 37, \mathrm{~K} 16 \rightarrow \mathrm{E} 11, \\
\mathrm{~L} 17 \rightarrow \mathrm{V} 36, \mathrm{~F} 19 \rightarrow \mathrm{L} 34, \mathrm{E} 22 \rightarrow \mathrm{N} 27, \mathrm{~N} 27 \rightarrow \mathrm{F} 20, \mathrm{~K} 28 \rightarrow \mathrm{E} 22, \mathrm{~L} 34 \rightarrow \mathrm{F} 19, \\
\mathrm{~V} 36 \rightarrow \mathrm{L} 17, \mathrm{~V} 40 \rightarrow \mathrm{Y} 10\end{array}$ \\
\hline 3 & 10 & $\begin{array}{l}\mathrm{Q} 15 \rightarrow \mathrm{V} 36, \mathrm{~K} 16 \rightarrow \mathrm{H} 13, \mathrm{~V} 18 \rightarrow \mathrm{L} 34, \mathrm{~A} 21 \rightarrow \mathrm{A} 30, \mathrm{G} 25 \rightarrow \mathrm{D} 23, \mathrm{G} 25 \rightarrow \mathrm{D} 23, \\
\mathrm{~S} 26 \rightarrow \mathrm{D} 23, \mathrm{G} 29 \rightarrow \mathrm{S} 26, \mathrm{~A} 30 \rightarrow \mathrm{A} 21, \mathrm{I} 32 \rightarrow \mathrm{F} 19\end{array}$ \\
\hline 4 & 15 & $\begin{array}{l}\mathrm{V} 12 \rightarrow \mathrm{G} 38, \mathrm{H} 13 \rightarrow \mathrm{G} 37, \mathrm{H} 13 \rightarrow \mathrm{Q} 15, \mathrm{H} 14 \rightarrow \mathrm{H} 13, \mathrm{H} 14 \rightarrow \mathrm{H} 14, \mathrm{~K} 16 \rightarrow \mathrm{G} 37, \\
\mathrm{~K} 16 \rightarrow \mathrm{E} 11, \mathrm{~L} 17 \rightarrow \mathrm{V} 36, \mathrm{~F} 19 \rightarrow \mathrm{L} 34, \mathrm{D} 23 \rightarrow \mathrm{E} 22, \mathrm{~K} 28 \rightarrow \mathrm{D} 23, \mathrm{~K} 28 \rightarrow \mathrm{D} 23, \\
\mathrm{~L} 34 \rightarrow \mathrm{F} 19, \mathrm{~V} 36 \rightarrow \mathrm{L} 17, \mathrm{~V} 40 \rightarrow \mathrm{Y} 10\end{array}$ \\
\hline & & \\
\hline 1 & 16 & $\begin{array}{l}\mathrm{Y} 10 \rightarrow \mathrm{A} 21, \mathrm{Y} 10 \rightarrow \mathrm{D} 23, \mathrm{Y} 10 \rightarrow \mathrm{D} 23, \mathrm{~V} 12 \rightarrow \mathrm{F} 19, \mathrm{H} 13 \rightarrow \mathrm{E} 11, \mathrm{H} 14 \rightarrow \mathrm{L} 17, \\
\mathrm{~L} 17 \rightarrow \mathrm{H} 14, \mathrm{~F} 19 \rightarrow \mathrm{V} 12, \mathrm{~F} 20 \rightarrow \mathrm{G} 33, \mathrm{~A} 21 \rightarrow \mathrm{Y} 10, \mathrm{D} 23 \rightarrow \mathrm{N} 27, \mathbf{N 2 7} \rightarrow \mathbf{D 2 3}, \\
\mathrm{N} 27 \rightarrow \mathrm{G} 25, \mathrm{M} 35 \rightarrow \mathrm{F} 20, \mathrm{~V} 36 \rightarrow \mathrm{M} 35, \mathrm{~V} 40 \rightarrow \mathrm{G} 38\end{array}$ \\
\hline 2 & 12 & $\begin{array}{l}\mathrm{Y} 10 \rightarrow \mathrm{A} 21, \mathrm{Y} 10 \rightarrow \mathrm{D} 23, \mathrm{~V} 12 \rightarrow \mathrm{F} 19, \mathrm{H} 14 \rightarrow \mathrm{L} 17, \mathrm{~L} 17 \rightarrow \mathrm{H} 14, \mathrm{~F} 19 \rightarrow \mathrm{V} 12, \\
\mathrm{~F} 20 \rightarrow \mathrm{I} 32, \mathrm{~A} 21 \rightarrow \mathrm{Y} 10, \mathrm{D} 23 \rightarrow \mathrm{N} 27, \mathrm{~S} 26 \rightarrow \mathrm{D} 23, \mathrm{~N} 27 \rightarrow \mathbf{D} 23, \mathrm{~L} 34 \rightarrow \mathrm{F} 20\end{array}$ \\
\hline 3 & 16 & $\begin{array}{l}\mathrm{Q} 15 \rightarrow \mathrm{G} 38, \mathrm{~L} 17 \rightarrow \mathrm{M} 35, \mathrm{~F} 19 \rightarrow \mathrm{G} 33, \mathrm{~A} 21 \rightarrow \mathrm{A} 30, \mathrm{D} 23 \rightarrow \mathrm{N} 27, \mathrm{~V} 24 \rightarrow \mathrm{D} 23, \\
\mathrm{~S} 26 \rightarrow \mathrm{D} 23, \mathrm{~S} 26 \rightarrow \mathrm{G} 25, \mathrm{~N} 27 \rightarrow \mathrm{D} 23, \mathrm{~N} 27 \rightarrow \mathrm{V} 24, \mathrm{G} 29 \rightarrow \mathrm{A} 21, \mathrm{I} 32 \rightarrow \mathrm{F} 19 \\
\mathrm{G} 33 \rightarrow \mathrm{F} 19, \mathrm{M} 35 \rightarrow \mathrm{L} 17, \mathrm{G} 37 \rightarrow \mathrm{G} 15, \mathrm{~V} 40 \rightarrow \mathrm{H} 13\end{array}$ \\
\hline 4 & 9 & $\begin{array}{l}\mathrm{V} 12 \rightarrow \mathrm{G} 38, \mathrm{H} 13 \rightarrow \mathrm{E} 11, \mathrm{~V} 18 \rightarrow \mathrm{L} 34, \mathrm{~S} 26 \rightarrow \mathrm{D} 23, \mathrm{~S} 26 \rightarrow \mathrm{D} 23, \mathrm{~L} 34 \rightarrow \mathrm{V} 18, \\
\mathrm{~V} 36 \rightarrow \mathrm{K} 16, \mathrm{G} 38 \rightarrow \mathrm{V} 12, \mathrm{~V} 40 \rightarrow \mathrm{Y} 10\end{array}$ \\
\hline
\end{tabular}

TABLE III. Hydrogen bonds in highest ranked clusters (first residue donor, second acceptor). $\alpha$-helical hydrogen bonds highlighted in bold. 


\section{Effects of AWI on Fragment Conformation}

Shown in Figure 7 are the secondary structure propensities for the $\mathrm{A} \beta(16-22)$ and $\mathrm{A} \beta(25-$ $35)$ fragments. Similar to the $\mathrm{A} \beta(10-40)$ peptide adsorption at the AWI changes the secondary structure propensity. For both these smaller fragments this is primarily an increase in the proportion of turn residues, caused by an increase in the probability of backbone hydrogen bonding at the AWI. In the A $\beta(16-22)$ the probabilities of the F20-V18 and A21-L17 hydrogen bonds are significantly higher then in solution. For the A $\beta(25-35)$ fragment there is an increase in the probability of L34-I32 hydrogen bonds, increasing the propensity for turn in the second half of the peptide.
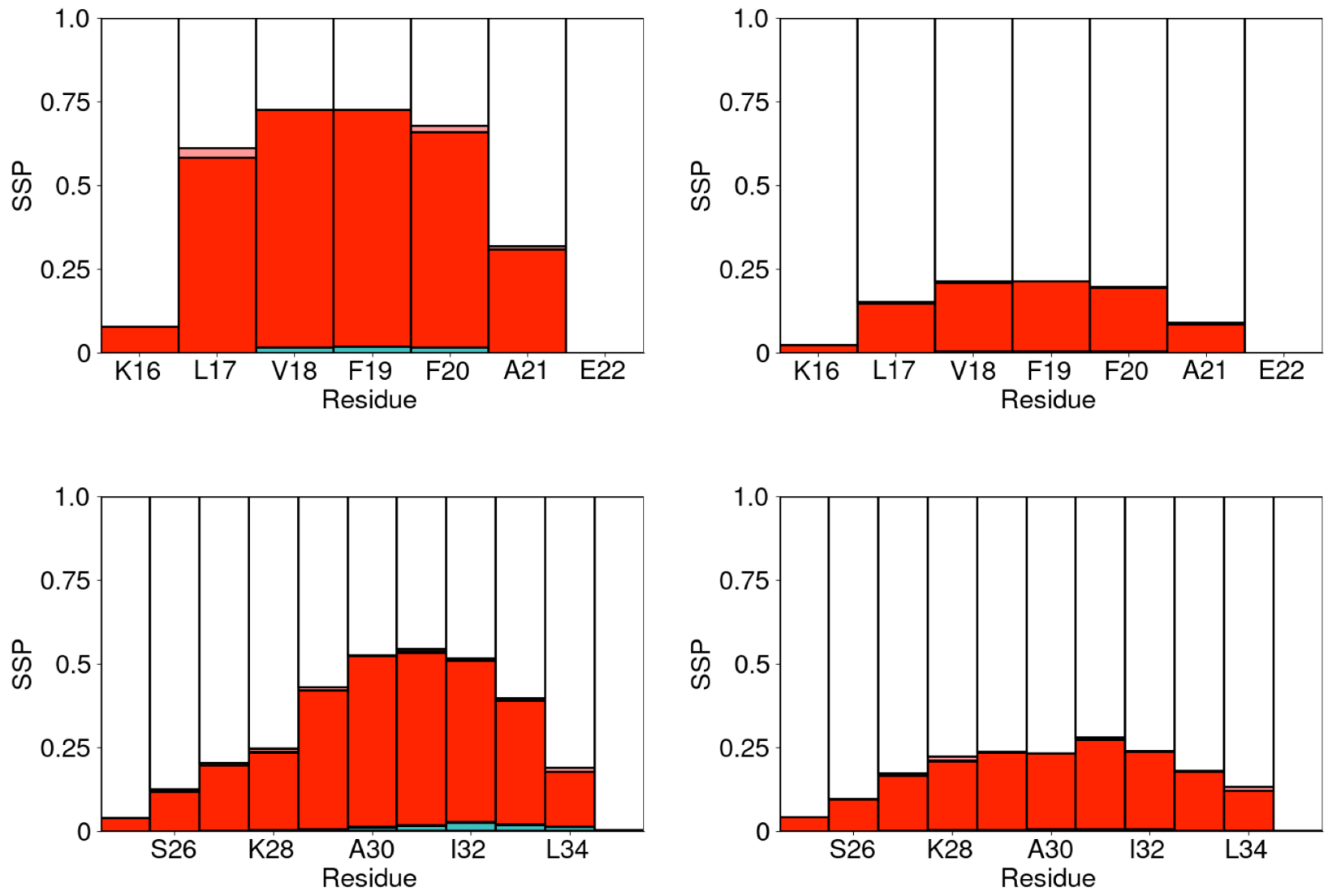

FIG. 7. Secondary structure propensity for each residue (averaged over last $200 \mathrm{~ns}$ of simulations) at AWI (left) and in bulk solution (right). Top and bottom show A $\beta(16-22)$ and $\mathrm{A} \beta(25-35)$ respectively. Colours as in Figure 1. 
Notably for both these fragments the secondary structures are different than in the larger A $\beta(10-40)$ system (Figure 1(b)). Partially this can be attributed to these fragments being too short to sustain helices or strands. For the $\mathrm{A} \beta(16-22)$ fragment the most significant structural feature is often considered to be the F19-F20 diphenylalanine motif. Containing two hydrophobic side chains the conformation of this significantly affected by the AWI. Shown in Figure 8 is the probability distribution of the angle between these two sidechains. Compared to bulk solution at the AWI this distribution is shifted towards cis states, similar to previous studies of $\mathrm{A} \beta(16-22)$ on gold surfaces ${ }^{25}$ and the diphenylalanine molecule at the water-cyclohexane interface $^{48}$. This allows both these sidechains to partition into the air, which further stabilises turn conformations. For the larger A $\beta(10-40)$ fragment tendency for cis conformations at the AWI is weaker as the adoption of cis-states leads to more unfavourable interactions for the rest of the molecule.
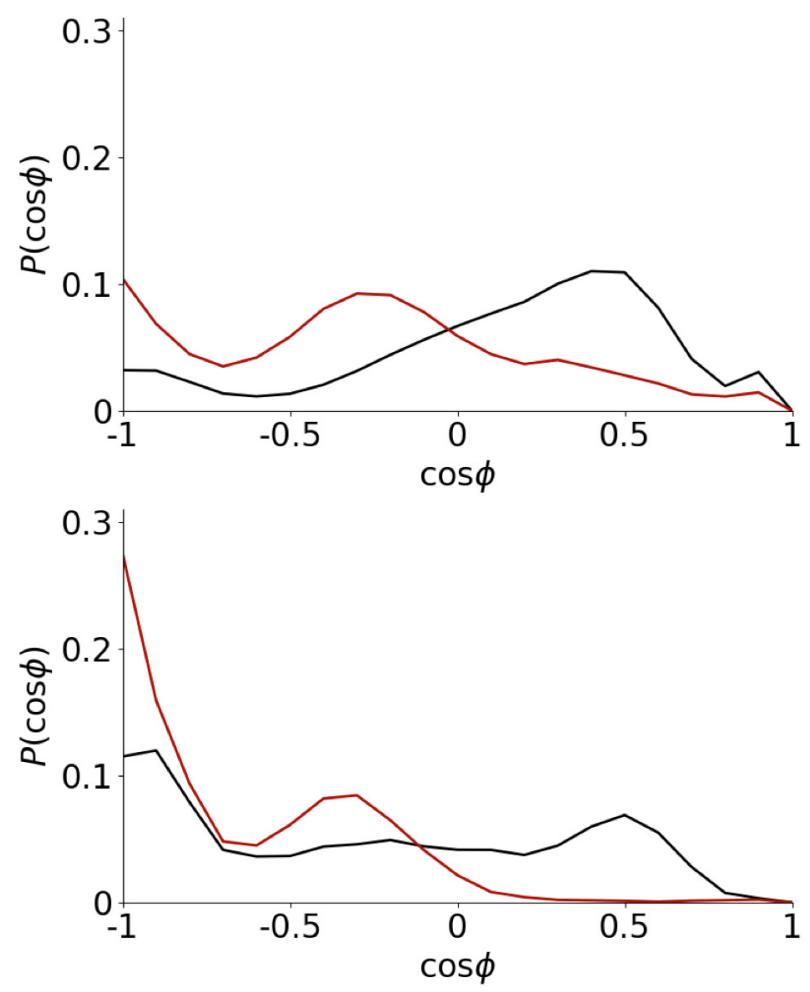

FIG. 8. Histogram of F19-F20 orientation for A $\beta$ (16-22) (top) and A $\beta(10-40)$ (bottom). AWI and solution data shown in black and red respectively.

There is a smaller difference in the secondary structure propensity for the $\mathrm{A} \beta(25-35)$ region in the small and large fragments. The first half of this region (G25-G29) is mostly turn 
(AWI) or random coil (solution) in both cases. Formation of turn, rather than $\alpha$-helix or $\beta$-strand, is due to the lose of interactions that stabilise these structures that are found in the $\mathrm{A} \beta(10-40)$ system.

Despite the differences in the secondary structure the tertiary structures of these fragments are similar to the equivalent regions in the (Table IV). For both fragments there is a slight decrease in $R_{g}$ and $G_{\max }$, particularly in bulk solution. The tendency of the AWI to induce more structured conformations may be reducing the differences in tertiary structure between the smaller and larger fragments. Consistent with the loss of helical structures $N_{\alpha-H B}$ and $N_{3-10}$ are both lower for $\mathrm{A} \beta(16-22)$ and $\mathrm{A} \beta(25-35)$ than for the equivalent regions in $\mathrm{A} \beta(10-40)$.

\section{CONCLUSIONS}

Protein aggregation has long been recognised as being enhanced at liquid (e.g. air-water, oil-water) interfaces. One driving force for this is the interface templating the formation of aggregation-prone conformations. This is particularly true for intrinsically disordered proteins, which typically lack a well defined structure in bulk solution. Using molecular dynamics simulation we found that the model fibril forming protein amyloid-beta can adopt $\alpha$-helical conformations at the AWI; this formation of ordered conformations at the AWI is consistent with other IDPs, and contrary to the loss of structure often seen for globular proteins $^{49}$.

The formation of helical structures at hydrophobic interfaces has been observed for a number of intrinsically disordered proteins ${ }^{20,46}$, suggesting that this is a common feature. Indeed experimental investigation of $\mathrm{A} \beta^{8,45}$ have identified $\alpha$-helical intermediates as a key step in its interfacial aggregation. As these helices are commonly amphipathic the exposed hydrophobic faces can make these more prone to aggregation. Notably only one of the two helices formed at the AWI is amphipathic (V12-D23), with the other consisting of solely hydrophobic amino acids.

As an intrinsically disordered protein $\mathrm{A} \beta$ exhibits a number of distinct conformations, both at AWI and in bulk solution. The number of conformations is significantly reduced at the AWI compared to bulk solution, due to the partitioning of hydrophobic side chains into the air. There is also little overlap between the sets of conformations in these two 


\begin{tabular}{|c|c|c|c|c|}
\hline $\mathrm{A} \beta(16-22)$ & AWI (frag) & AWI (full) & Solution (frag) & Solution (full) \\
\hline$R_{g} / \AA$ & $5.7 \pm 0.4$ & $6.1 \pm 0.7$ & $6.6 \pm 0.6$ & $7.5 \pm 0.4$ \\
\hline$G_{\max } / \AA$ & $4.4 \pm 0.5$ & $4.9 \pm 1.1$ & $5.6 \pm 0.9$ & $7.0 \pm 0.6$ \\
\hline$G_{m i d} / \AA$ & $3.2 \pm 0.3$ & $3.2 \pm 0.3$ & $3.0 \pm 0.4$ & $2.5 \pm 0.3$ \\
\hline$G_{\min } / \AA$ & $2.2 \pm 0.3$ & $2.1 \pm 0.4$ & $2.1 \pm 0.3$ & $1.9 \pm 0.2$ \\
\hline$N_{C \alpha}$ & $17 \pm 2$ & $16 \pm 3$ & $14 \pm 1.5$ & $12.4 \pm 0.4$ \\
\hline$N_{C \gamma}$ & $4.6 \pm 0.7$ & $3.8 \pm 0.6$ & $4.0 \pm 0.7$ & $3.2 \pm 0.7$ \\
\hline$N_{\alpha-H B}$ & $0.2 \pm 0.3$ & $1.0 \pm 1.2$ & $0.0 \pm 0.1$ & $0 \pm 0$ \\
\hline$N_{3-10}$ & $0.5 \pm 0.4$ & $0.8 \pm 0.9$ & $0.2 \pm 0.2$ & $0.05 \pm 0.03$ \\
\hline$D H$ & $6.8 \pm 0.9$ & $6.1 \pm 2.4$ & $8.2 \pm 1.0$ & $9.4 \pm 0.4$ \\
\hline $\mathrm{A} \beta(25-35)$ & AWI (frag) & AWI (full) & Solution (frag) & Solution (full) \\
\hline$R_{g} / \AA$ & $7.4 \pm 1.1$ & $7.4 \pm 1.3$ & $8.1 \pm 1.2$ & $8.6 \pm 0.8$ \\
\hline$G_{\max } / \AA$ & $6.3 \pm 1.3$ & $6.3 \pm 1.4$ & $7.2 \pm 1.5$ & $7.3 \pm 1.2$ \\
\hline$G_{m i d} / \AA$ & $3.5 \pm 0.5$ & $3.2 \pm 0.5$ & $3.4 \pm 0.5$ & $3.8 \pm 0.8$ \\
\hline$G_{\min } / \AA$ & $2.3 \pm 0.3$ & $2.3 \pm 0.3$ & $2.2 \pm 0.3$ & $2.2 \pm 0.2$ \\
\hline$N_{C \alpha}$ & $31 \pm 5$ & $32 \pm 5$ & $28 \pm 4$ & $26 \pm 6$ \\
\hline$N_{C \gamma}$ & $4.5 \pm 1.1$ & $4.3 \pm 1.3$ & $3.7 \pm 1.0$ & $3.1 \pm 0.6$ \\
\hline$N_{\alpha-H B}$ & $0.2 \pm 0.5$ & $1.1 \pm 1.2$ & $0.1 \pm 0.1$ & $0.05 \pm 0.05$ \\
\hline$N_{3-10}$ & $0.6 \pm 0.5$ & $1.1 \pm 0.9$ & $0.3 \pm 0.3$ & $0.3 \pm 0.3$ \\
\hline$D H$ & $12.2 \pm 1.7$ & $11.4 \pm 2.3$ & $13.5 \pm 1.3$ & $14.0 \pm 1.0$ \\
\hline
\end{tabular}

TABLE IV. Comparison between structures of $\mathrm{A} \beta(16-22)$ and $\mathrm{A} \beta(25-35)$ fragments and equivalent regions in $\mathrm{A} \beta(10-40)$.

environments. This suggests that $\mathrm{A} \beta$ exhibits induced fit-like ${ }^{50}$ behaviour at hydrophobic interfaces, in common with other IDPs.

Comparison between the smaller $(\mathrm{A} \beta(16-22)$ and $\mathrm{A} \beta(25-35))$ and larger $(\mathrm{A} \beta(10-40))$ fragments illustrate the influence of the larger protein structure conformational behaviour. Both the smaller fragments show an increase in the propensity for ordered secondary structure, in common with the larger fragment, but for both the smaller fragments this is predominately turn as they are too short to form stable helical or extended structures, at least as 
monomers. In the case of A $\beta(16-22)$ fragment the difference in secondary structure is further driven by the increased adoption of cis-conformations of the F19-F20 diphenylalanine motif at the AWI.

While the AWI provides a simple model of a hydrophobic/hydrophilic interface we would expect amyloid beta, and other amyloidogenic proteins, to exhibit similar behaviour at other more complex interfaces. Within biological systems proteins can encounter a variety interfaces, most notably the cell membrane. These can often act to induce protein conformational change and aggregation, which is implicated in cell damage caused by amyloidogenic proteins. Knowledge of the conformation of amyloid beta at interfaces can then be used to give insight into fibril formation on other biological environments. Surfaces and interfaces are also commonly used in the preparation of protein structures, such as fibrils, for use in materials science and biotechnological applications, where the enhancement of fibrillation is advantageous.

\section{ACKNOWLEDGEMENTS}

Computational facilities for this work were provided by the SFI/HEA funded Irish Centre for High End Computing. SS was supported by a postgraduate research scholarship from the College of Science, NUI Galway.

\section{DATA AVAILABILITY}

The data that support the findings of this study are available from the corresponding author upon reasonable request.

\section{APPENDIX - SIMULATION SAMPLING AND CONVERGENCE}

Motion of trajectories between replicas can be monitored through the variation of the REST scaling parameter $\left(\beta_{i}\right)$ for different replicas (Figure 9)) for $\mathrm{A} \beta(10-40)$. As can be seen the replicas explore different values of $\beta_{i}$. Shown in Table $\mathrm{V}$ are the acceptance rates for the simulations. In all cases the acceptance rates are above $20 \%$ for all simulations and all pairs of replicas. 


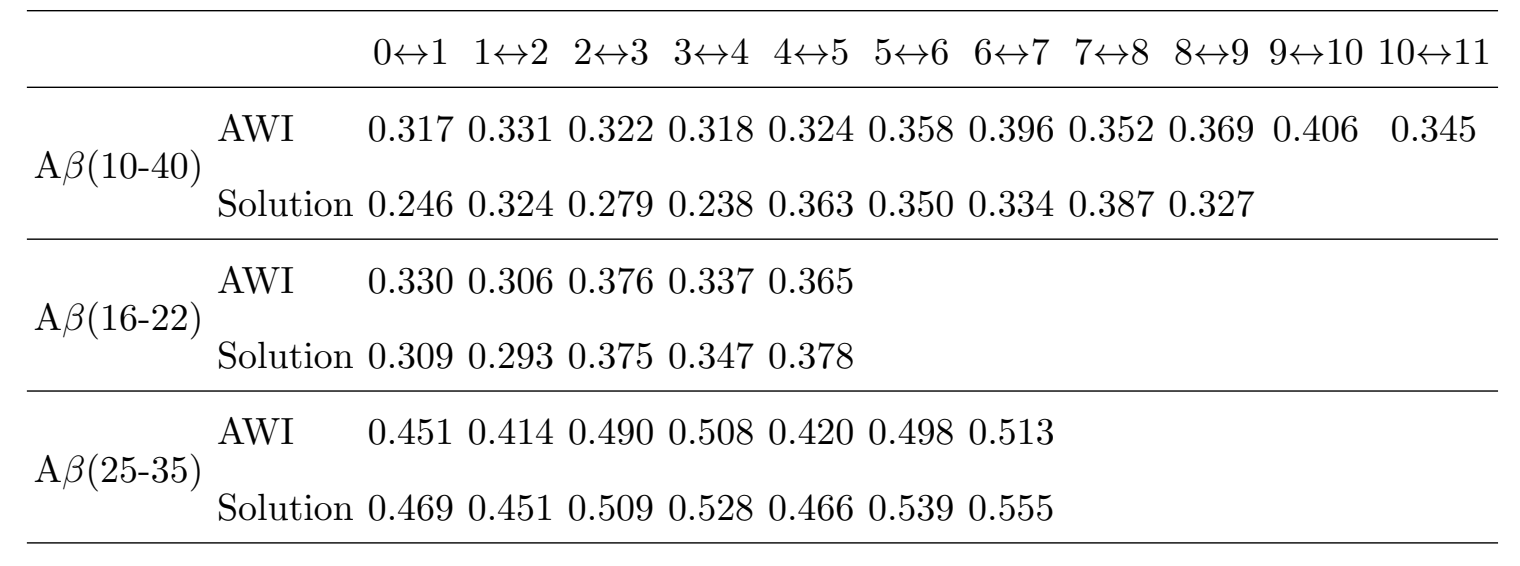

TABLE V. Acceptance rates for REST simulations.

To see whether the conformational ensemble has been well sampled the number of unique conformations found (using cluster analysis) against simulation for $\mathrm{A} \beta(10-40)$ is shown in Figure 10). As can be seen the number of clusters within $3 \mathrm{kcal} \mathrm{mol}^{-1}$ of most common cluster has plateaued within 200 ns for the AWI simulation and 300 ns for bulk solution, suggesting adequate sampling of the conformational ensemble. 

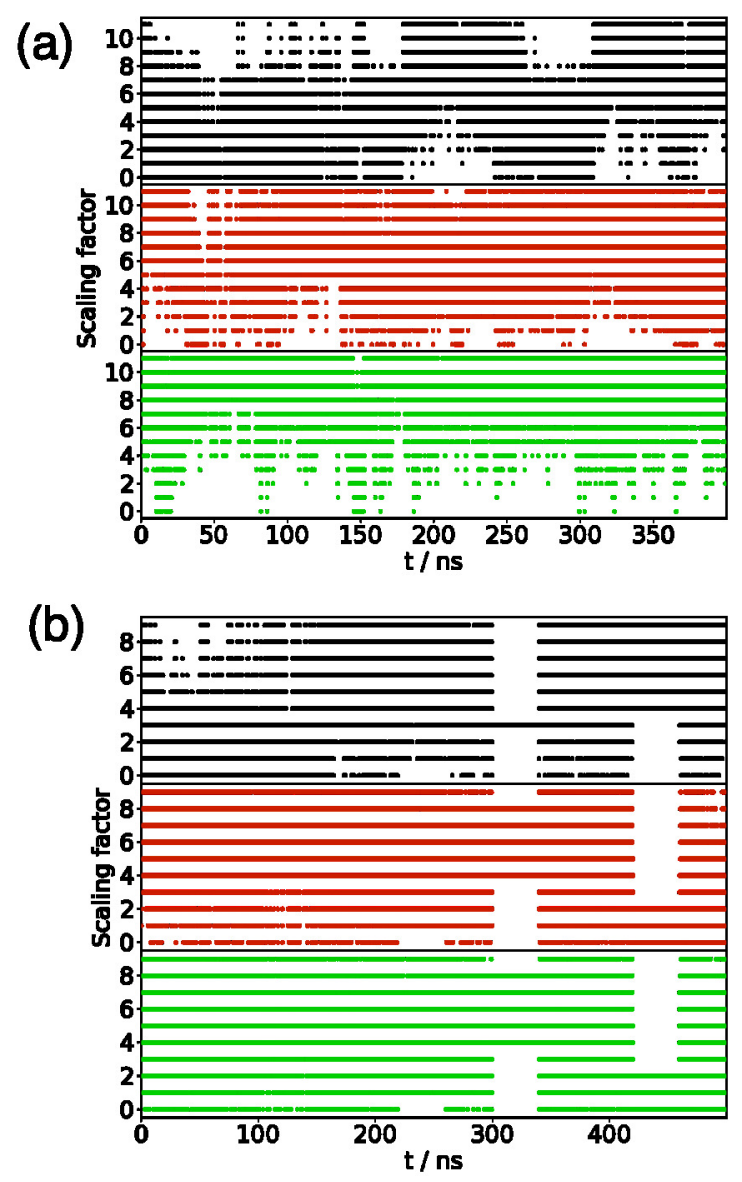

FIG. 9. (a) Plot of scaling factor ( $i$ denotes $\beta_{i}$ ) for $\mathrm{A} \beta(10-40)$ at AWI. Graphs show (from top to bottom) replicas with $i=0,6$, and 11 at $t=0$. (b) Plot of scaling factor $\left(i\right.$ denotes $\left.\beta_{i}\right)$ for $\mathrm{A} \beta(10-40)$ in bulk solution. Graphs show (from top to bottom) replicas with $i=0,5$, and 9 at $t=0$. 


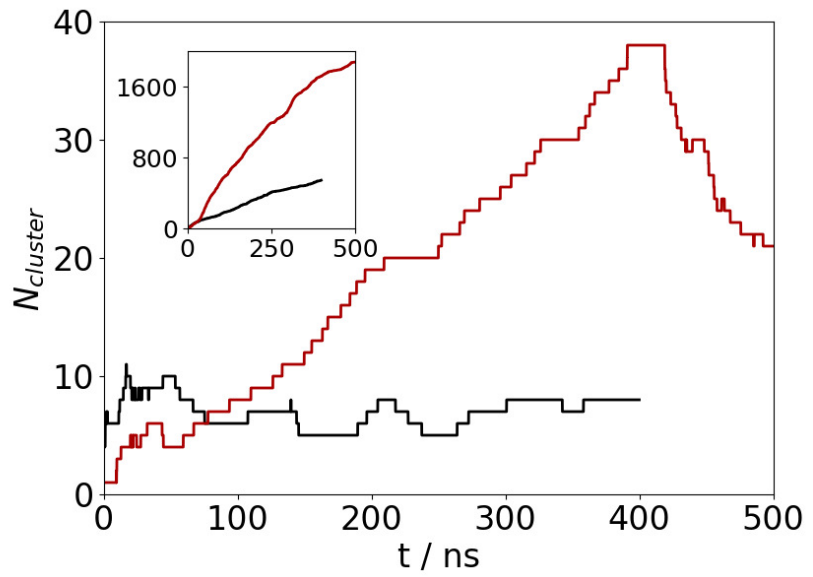

FIG. 10. Number of unique clusters against time for A $\beta(10-40)$ at AWI (black) and in bulk solution (red). Main panel shows number of clustes within $3 \mathrm{kcal} \mathrm{mol}^{-1}$ of most common cluster, inset shows total number of clusters. 
* david.cheung@nuigalway.ie

1 F. Chiti and C. M. Dobson, Annual Review of Biochemistry 75, 333 (2006), ISSN 0066-4154, URL http://www. annualreviews.org/doi/10.1146/annurev.biochem.75.101304.123901.

2 M. G. Iadanza, M. P. Jackson, E. W. Hewitt, N. A. Ranson, and S. E. Radford, Nat Rev Mol Cell Biol 19, 755 (2018), ISSN 1471-0072, 1471-0080, URL http://www.nature.com/ articles/s41580-018-0060-8.

3 M. D. Benson, J. N. Buxbaum, D. S. Eisenberg, G. Merlini, M. J. M. Saraiva, Y. Sekijima, J. D. Sipe, and P. Westermark, Amyloid 25, 215 (2018), ISSN 1350-6129, 1744-2818, URL https://www.tandfonline.com/doi/full/10.1080/13506129.2018.1549825.

4 T. P. J. Knowles and R. Mezzenga, Advanced Materials 28, 6546 (2016), ISSN 15214095.

5 C. Li, R. Qin, R. Liu, S. Miao, and P. Yang, Biomater. Sci. 6, 462 (2018), ISSN 2047-4830, 2047-4849, URL http://xlink.rsc.org/?DOI=C7BM01124E.

6 C. Schladitz, E. P. Vieira, H. Hermel, and H. Möhwald, Biophysical Journal 77, 3305 (1999), ISSN 00063495, URL http://linkinghub.elsevier.com/retrieve/pii/ S0006349599771614.

7 A. Morinaga, K. Hasegawa, R. Nomura, T. Ookoshi, D. Ozawa, Y. Goto, M. Yamada, and H. Naiki, Biochim. Biophys. Acta - Proteins Proteomics 1804, 986 (2010), ISSN 15709639, URL http://dx.doi.org/10.1016/j.bbapap.2010.01.012.

8 M. Hoernke, J. A. Falenski, C. Schwieger, B. Koksch, and G. Brezesinski, Langmuir 27, 14218 (2011).

9 S. Campioni, G. Carret, S. Jordens, L. Nicoud, R. Mezzenga, and R. Riek, J. Am. Chem. Soc. 136, $2866(2013)$.

10 L. Jean, C. F. Lee, C. Lee, M. Shaw, and D. J. Vaux, The FASEB Journal 24, 309 (2010), ISSN 0892-6638, URL http://www.fasebj.org/cgi/doi/10.1096/fj.09-137653.

11 L. Jean, C. F. Lee, and D. J. Vaux, Biophysical journal 102, 1154 (2012), ISSN 1542-0086, URL http://www.ncbi.nlm.nih.gov/pubmed/22404938.

12 N. B. Last, E. Rhoades, and A. D. Miranker, Proceedings of the National Academy of Sciences 108, 9460 (2011), ISSN 0027-8424, URL http://www.pnas.org/cgi/doi/10.1073/ pnas. 1102356108 . 
13 S. Hosseinpour, S. J. Roeters, M. Bonn, W. Peukert, S. Woutersen, and T. Weidner, Chem. Rev. p. acs.chemrev.9b00410 (2020), ISSN 0009-2665, 1520-6890, URL https://pubs.acs . org/doi/abs/10.1021/acs . chemrev.9b00410.

14 F. A. Husband, M. J. Garrood, A. R. Mackie, G. R. Burnett, and P. J. Wilde, Journal of Agricultural and Food Chemistry 49, 859 (2001), ISSN 00218561.

15 A. J. Miles and B. A. Wallace, Chemical Society reviews 35, 39 (2006), ISSN 0306-0012.

16 D. J. Earl and M. W. Deem, Physical Chemistry Chemical Physics 7, 3910 (2005).

17 A. Laio and F. L. Gervasio, Rep. Prog. Phys. 71, 126601 (2008).

18 D. L. Cheung, Langmuir 32, 4405 (2016), ISSN 0743-7463, URL http://pubs.acs.org/doi/ abs/10.1021/acs. langmuir.5b04619.

19 D. L. Cheung, Journal of Chemical Physics 147, 195101 (2017), ISSN 00219606.

20 D. L. Cheung, J. Chem. Phys. 151, 064706 (2019), ISSN 0021-9606, 1089-7690, URL http: //aip.scitation.org/doi/10.1063/1.5100253.

21 M. Deighan and J. Pfaendtner, Langmuir 29, 7999 (2013).

22 D. L. Cheung, Biointerphases 15, 051001 (2020).

23 A. K. Paravastu, R. D. Leapman, W.-m. Yau, and R. Tycko, Proc. Natl. Acad. Sci. 105, 18349 (2008).

24 L. Millucci, L. Ghezzi, G. Bernardini, and A. Santucci, Current Protein and Peptide Science 11, $54(2010)$.

25 L. Bellucci, A. Ardèvol, M. Parrinello, H. Lutz, H. Lu, T. Weidner, and S. Corni, Nanoscale 8, 8737 (2016), ISSN 2040-3364, 2040-3372, URL http://xlink.rsc.org/?DOI=C6NR01539E.

26 L. Bellucci, G. Bussi, R. Di Felice, and S. Corni, Nanoscale 9, 2279 (2017), ISSN 2040-3364, URL http://xlink.rsc.org/?DOI=C6NR06010B.

27 O. Crescenzi, S. Tomaselli, R. Guerrini, S. Salvadori, A. M. D’Ursi, P. A. Temussi, and D. Picone, European Journal of Biochemistry 269, 5642 (2002), ISSN 00142956, URL http: //doi.wiley.com/10.1046/j.1432-1033.2002.03271.x.

28 A. M. D'Ursi, M. R. Armenante, R. Guerrini, S. Salvadori, G. Sorrentino, and D. Picone, Journal of medicinal chemistry 47, 4231 (2004), ISSN 0022-2623.

29 P. Liu, B. Kim, R. A. Friesner, and B. J. Berne, Proceedings of the National Academy of Sciences of the United States of America 102, 13749 (2005), ISSN 0027-8424, URL http: //www.pnas.org/cgi/content/long/102/39/13749. 
30 L. Wang, R. A. Friesner, and B. J. Berne, Journal of Physical Chemistry B 115, 9431 (2011), ISSN 15205207.

31 Y. Sugita and Y. Okamoto, Chemical Physics Letters 314, 141 (1999), ISSN 1064-3745, URL http://www.ncbi.nlm.nih.gov/pubmed/16957325.

32 A. K. Smith, C. Lockhart, and D. K. Klimov, Journal of Chemical Theory and Computation 12, 5201 (2016), ISSN 15499626.

33 G. Bussi, D. Donadio, and M. Parrinello, Journal of Chemical Physics 126, 014101/1 (2007), ISSN 00219606.

34 M. Parrinello and A. Rahman, Journal of Applied Physics 52, 7182 (1981), ISSN 00218979.

35 U. Essmann, L. Perera, M. L. Berkowitz, T. Darden, H. Lee, and L. G. Pedersen, Journal of Chemical Physics 103, 8577 (1995).

36 B. Hess, H. Bekker, H. J. C. Berendsen, and J. G. E. M. Fraaije, Journal of computational chemistry 18, 1463 (1997).

37 D. Van Der Spoel, E. Lindahl, B. Hess, G. Groenhof, A. E. Mark, and H. J. C. Berendsen, Journal of Computational Chemistry 26, 1701 (2005), ISSN 01928651.

38 B. Hess, C. Kutzner, D. van der Spoel, and E. Lindahl, J. Chem. Theory Comput. 4, 435 (2008), ISSN 15499618, URL http://pubs.acs.org/doi/abs/10.1021/ct700301q.

39 M. J. Abraham, T. Murtola, R. Schulz, S. Páll, J. C. Smith, B. Hess, and E. Lindahl, SoftwareX 1-2, 19 (2015), ISSN 23527110, URL https://linkinghub.elsevier.com/retrieve/ pii/S2352711015000059.

40 G. A. Tribello, M. Bonomi, D. Branduardi, C. Camilloni, and G. Bussi, Computer Physics Communications 185, 604 (2014), ISSN 00104655, URL http://dx.doi.org/10.1016/j.cpc. 2013.09 .018$.

41 X. Daura, K. Gademann, B. Jaun, D. Seebach, W. F. Van Gunsteren, and A. E. Mark, Angew. Chemie Int. Ed. 38, 236 (1999), ISSN 1433-7851, URL http://doi.wiley.com/10.1002/(SICI) 1521-3773(19990115)38:1/2\%7B\%25\%7D3C236: : AID-ANIE236\%7B\%25\%7D3E3.0.CD;2-M.

42 N. Michaud-Agrawal, E. J. Denning, T. B. Woolf, and O. Beckstein, Journal of computational chemistry 32, 2319 (2011), ISSN 1096-987X.

43 W. Humphrey, A. Dalke, and K. Schulten, Journal of Molecular Graphics 14, 33 (1996), ISSN 02637855, URL http://dx.doi.org/10.1016/0263-7855(96)00018-5. 
44 M. Heinig and D. Frishman, Nucleic Acids Research 32, 500 (2004), ISSN 03051048.

45 D. Jiang, K. L. Dinh, T. C. Ruthenburg, Y. Zhang, L. Su, D. P. Land, and F. Zhou, J. Phys. Chem. B 113, 3160 (2009).

46 A. De Simone, C. Kitchen, A. H. Kwan, M. Sunde, C. M. Dobson, and D. Frenkel, Proceedings of the National Academy of Sciences of the United States of America 109, 6951 (2012), ISSN 0027-8424.

47 C. Dalgicdir, C. Globisch, C. Peter, and M. Sayar, PLOS Computational Biology 11, e1004328 (2015), ISSN 1553-7358, URL http://dx.plos.org/10.1371/journal.pcbi.1004328.

48 C. Dalgicdir, O. Sensoy, C. Peter, and M. Sayar, The Journal of chemical physics 139, 234115 (2013), ISSN 1089-7690, URL http://www.ncbi.nlm.nih.gov/pubmed/24359360.

49 M. Stefani, International Journal of Molecular Sciences 9, 2515 (2008), ISSN 14220067.

50 D. E. Koshland, Proc. Natl. Acad. Sci. 44, 98 (1958). 